\title{
Erratum to: The role of taurine in renal disorders
}

\author{
Xiaobin Han $\cdot$ Russell W. Chesney
}

Published online: 20 December 2013

(C) Springer-Verlag Wien 2013

\section{Erratum to: Amino Acids (2012) 43:2249-2263 DOI 10.1007/s00726-012-1314-y}

This article is part of the Special Issue "Clinical significance of taurine" edited by S. Schaffer while it was published already in print in Volume 43, Issue 6.

Abstract This article examines the actions of taurine on
models of renal dysfunction, the potential mechanisms of
taurine action and the possible clinical significance of these
findings. Our laboratory has written previously on the role
of taurine in renal function and we have focused upon the
normal physiology of the kidney and on the mechanisms
and regulation of the renal transport of taurine. This review
is a distinct change of emphasis in that we describe a number of studies which have evaluated various aspects of renal dysfunction, including hypertension and proteinuria, specific glomerular and tubular disorders, acute and chronic renal conditions, urinary tract conditions including infection and nephrolithiasis, and diabetic nephropathy. The subject of chronic kidney disease and renal transplantation will also be examined relative to $b$ amino acid. The studies evaluated will be mainly recent ones, recognizing that older reviews of the role of taurine in the kidney are available.

Keywords Taurine · Renal function · Glomerular nephritis · Acute kidney injury · Diabetic nephropathy · Chronic kidney disease

The online version of the original article can be found under doi:10.1007/s00726-012-1314-y.

X. Han $\cdot$ R. W. Chesney $(\bowtie)$

Department of Pediatrics, The University of Tennessee Health

Science Center, and the Children's Foundation Research

Institute at Le Bonheur Children's Hospital, Memphis,

TN 38103, USA

e-mail: rchesney@uthsc.edu 